\title{
Study on the Coordinated Development of Local Colleges and Regional Economy in Gansu
}

\author{
Weiwei Guo ${ }^{1, a}$ \\ ${ }^{1}$ Economics and Management College, Longdong University, Qingyang, Gansu, 745000 \\ ${ }^{\mathrm{a}}$ email
}

Keywords: Local Colleges, Serve Local Government, Regional Economic Development

\begin{abstract}
Formerly Regional College in Gansu is mostly normal colleges and it is influenced by the traditional influence, widespread service area economy applied lack of professionals, small organizations, teachers' active participation is not high, Local Colleges succeed in Gansu universities bushes fierce competition recognized by society, we must improve the mechanism for all kinds of personnel and actively introduce, use a combination of self-nurturing, the establishment of regional economic and social development of the "expert database"; change idea, mining, actively establish various social organizations or research institutions to actively participate in local economic and social development; the establishment of social services focused on the ability of titles evaluation system.
\end{abstract}

\section{Introduction}

As one of the three basic functions of colleges and universities, economic and social development is the starting point and ultimate ownership. For in terms of backward regions located in the northwest Gansu Province, Local Colleges, a clear understanding of the situation of higher education reform, grasp the "restructuring and development" theme, always adhere to the principle of working "for the demand, optimize the structure, accelerate the construction, improve quality", optimization discipline system, optimizing the cultivation process, optimize the management system and mechanism, and actively reform educational philosophy of higher education, school system, management system and training model to explore the school characteristics and professional characteristics, the development focus from "large-scale expansion, the campus building" to "content development, and improve the quality of" change, go to the school of thought really serve up local economic and social development, to produce Teachings, school-enterprise cooperation up to go and cultivate technical talents come up, go up to enhance students' employability and entrepreneurial abilities comprehensively improve the educational level to promote regional industrial structure and the structure of higher education coordinated development work to adapt to the times demand of qualified university inevitable trend.

\section{The Regional College in Gansu Economic Social Profiles}

General Founded in Gansu late local colleges, each a small number of schools, small-scale, scattered distribution, low levels of culture. And its predecessor, mostly college, is the founding of New China in response to national policy, to address the high school teachers was a serious lack of plaque established. Longxi officially named as Normal School in 1950 and the beginning of founding of New China, Gansu Normal University, Gansu Teachers College, Teachers College, Lanzhou, Tianshui Normal College, Teachers College Pingliang, Dingxi Teachers College, Zhangye Teachers College, Linxia Teachers College and other departments in order to respond to the Ecole Normale Superieure and adjustment policies have been established, Teachers College, Lanzhou, Tianshui Normal College, Qingyang Teachers College, Zhangye Teachers College, co-national TEACHERS COLLEGE and so it is the "Cultural Revolution" have been established. These schools since the 1990s, with the reform of the economic system and the education system, many of the local normal universities actively professional settings for local economic construction and social development services, training multi-level professional talent, set up non-teacher professional, 
individual institutions and even non-teacher professional development as a school in transition focus breakthrough, non-teacher education in Normal disciplines than discipline. Many local institutions will "regional, applied" as the University Identity, began to change educational ideas, concise school characteristics, such as Longdong University is committed to "doing fine and stronger teacher professional, improve teacher education advantages; develop engineering professional, Cultivation of energy and chemical characteristics; and stable development of agriculture, forestry, biology major, and enhance the ability of local service; moderate development of applied Arts and the professional, to meet the diverse needs of society "; Tianshui Normal University is committed to" doing fine teacher education majors, engineering majors bigger, stronger application management specialty, and solid culture body art majors. " Although many local institutions of higher education in terms of educational ideas, orientation, location and other disciplines to make a positive adjustment, attention to service regional economic and social development, a considerable number of institutions only interested in professional settings, not for the community service organizations or groups, social services, economic development means weak, a lot of strategy is still in the conceptual stage or exploring, have not formed significant social benefits, and even part of the strategy has been questioned by the community. According to multi-understood, therefore, on the whole, the results of Gansu Local Colleges serve regional economic and social development of the very few attempts inadequate, not determined, it will require long-term efforts might be improved.

\section{The Regional College in Gansu Economic Social Problem Analysis}

Local University Teachers Gansu by long-term impact of educational experience, school thinking normal universities entrenched obstacles to a certain extent, the development of non-normal education. (1) teacher education is still an important function of local institutions and Gansu Gansu colleges serve the local Regional Economic basic survival. Closely follow the development of the law of the market economy, and actively adjust the professional structure, set up a multi-disciplinary type, it is the only way a traditional teacher professional colleges. However, if you simply give up, then, these schools would face years of hard-won advantage discipline in vain, because the establishment of new professional talent scarcity, lack of accumulation of results, and other issues difficult to drive the rapid development of the school, is likely to result in insufficient school students, disrepute dilemma. (2) Teachers in most schools will replicate in non-school educational experience normal, seriously hampered the development of non-teacher education. Too many teachers and teacher education emphasizes standardized behavior, teachers and students can easily result in rigid conservative, lack of innovation and passion, innovative thinking is not conducive to development. Therefore, you can not give up in teacher education, but also the case of the development of non-teacher education if the school can not flexible arrangements in the system, eventually making the non-teacher professional teachers to serve the community the ability to weaken the local institutions in the service area of economic and social development lack of personnel, which is also rare professor Gansu local Teachers Colleges "economic management" and other well-known experts in applied professional important reason. (3) the reputation of the relevant experts to serve on the regional economy is not high. Gansu Province, Local Colleges because of non-teacher professional teacher professional compared Established later, so most teachers titles is not high, is a serious shortage of the number of associate professors and other senior teachers, less accumulated scientific research, due to the heavy task of teaching social services caused by lack of experience, and the free flow of talent under the market economy mechanism, many senior teachers "southeastern", these factors severely restricted the ability of Local Colleges in Gansu serve regional economic and social development.

Due to Local Colleges are of Gansu Normal school of origin, non - teacher set up time later, summed up, the Local Colleges in Gansu common basic science research is weak, applied sciences building late start, lack of social services can have a solid research platform. As Longdong University School of Economics and Management, School of Economics and Management, Hexi University were established in 2010, Tianshui Normal University Business School, founded in 2014, 
the three institutions in Gansu Province as a typical representative of local institutions, not to mention no state-level key discipline, national key laboratories and research institutes, and even the provincial key disciplines, key laboratories and research institutes are pitiful, even if the individual research institutions, it is only the university or hospital-level research platform, showing that local governments its support is not enough. According to the college web page display, Hexi University School of Economics and Management regional economics, business management only university key disciplines, regional economics Longdong University School of Economics and Management under construction provincial key disciplines, and at the Laboratory Institute of building three institutions is still blank. The actual feedback of the whole Gansu Local Services Local Colleges economic and social development organization is less participation. While other local colleges such as Dingxi Teachers College, Longnan Teachers College, Teachers College and other ethnic cooperation in the service area of economic and social development of the organization are even scarcer.

State assessment of the local school level and efficiency of universities, mainly limited to personnel training level, the level of teaching, scientific research, educational basic conditions, employment and other indicators, and to local universities and social services, Local Colleges actual socio-economic development examine factors such as the role and influence is not enough. So the assessment standards, often overlooked social service function of education, the result not only can not fully reflect the true overall strength and level of Local Colleges, but to dispel the Local Colleges to serve the community's enthusiasm and motivation, is not conducive to local social services Universities carried out. Teachers and researchers in the job classification in general, are in teaching the subject, the paper is mainly based on its economic and social service activities in carrying out arduous labor and failed to produce the necessary and reasonable evaluation and service quality will not be reflected in their assessment and evaluation. This directly affects their bonus allocation, job classification, job promotion, so that teachers and researchers to a significant loss actively serve the local economic and social development momentum and has seriously hampered the further development of local universities' social services.

\section{Local Colleges in Gansu Economic Social Countermeasures}

WEST less talent local colleges, a serious loss is a common phenomenon, and this is particularly prominent in Gansu local colleges. According to my understanding of the Local Colleges in Gansu Longdong University, Hexi University of doctoral students admitted to serving teachers have already left more than half of the original school, colleges and universities to neighboring office. In a market economy, a serious brain drain of the most important reason is the lower Gansu local colleges give Dr treatment, according to Dr. schools website treatment, Dr. benefits provided by these two institutions is basically the same, that is about 100 square meters housing, financial relief 5-10 million, 3-5 million research start-up funds, and economic treatment of Shaanxi, Sichuan and other neighboring institutions offer twice the above condition is the worst, but in other aspects of the treatment of stealth neighboring colleges also Gansu local colleges give no better than poor. So, you want to get the reputation of Gansu from local colleges in the fierce competition in college, we must significantly improve senior, highly educated, high-profile experts and scholars of economic benefits, enhance the teachers' humanistic and spiritual aspects of care, and improve various types personnel system, the real erected for well-known professors, experts and scholars serve regional economic and social development research platform. In addition, many local governments should attach importance to the development of Local Colleges from the system, human resources, capital, technology, respect for the constructive comments benefit local political, economic, cultural, environmental health and other aspects of local Teachers College proposed the establishment of regional "expert database" economic and social development, the real scholar Professor "industry specializing in surgery" was "learned something" brought honor and pride, it will serve as a regional economic and social development "due diligence "instead of" nothing to do."

Features for local colleges to Gansu and level, must be based on local, relying on local, local services, make full use of geographical advantages, resources and industrial advantages, adjust the 
structure of academic disciplines, identify the direction of development suited to their discipline, setting professional counterparts, construction specialty, always adhere to the "local" in the direction of running and school characteristics, as the basis for survival and development. The main idea of school reform and development should focus on "local" orientation, highlighting the spirit of service to the local university, according to the macro planning of local government, local businesses understand the needs of professionals and future development planning, comprehensive investigation of school discipline construction, professional settings, scientific research, development, planning and so on. To local needs as a guide, combined Strengths and historical heritage, to determine the nature of the school, mission, educational goals and direction of development, the development of new economic development in schools serving regional social action plan, organize political and legal facing the region, economic and social, cultural and sports health, environment, resources and other research institutions to actively participate in the strategic development of the region's enterprises and institutions, business processes, research and other aspects of the problem, and incorporated into future development plans of the institutions included in the important work in teaching, research, talent culture, achievements in various fields to give full expression. Encourage college teachers to depth internal and strengthen horizontal research efforts, the initiative to undertake research companies need to be resolved.

Scientific evaluation mechanism is to inspire social consciousness of University Teachers services to enhance the level of an important factor in social services. Local Colleges should serve economic and social development into the evaluation system, according to the way social services, capabilities and benefits of establishing a rational evaluation, and with the professional title engagement, promotions, selection of supervisors and allowances allocation linked to inspire teachers to effectively carry out social services work enthusiasm and initiative. Establishment of Academic Committee, Academic Degrees Committee alongside Social Services Committee, and actively explore new ideas, new modes of cooperation with government agencies, enterprises and institutions, public organizations and other institutions, colleges and universities to improve and expand the functions of the social services administration, from various aspects of the system, funding, platform construction for local teachers and researchers institutions offer a broader cooperation channels, the progressive realization of social services by the College dispensable to the spontaneous behavior of individuals is essential, organized, planned , leadership collective behavior change. The importance of teacher capacity and effectiveness of social services in the job classification of the highlights, reasonable definition of local university teachers hosted by enterprises, public organizations lateral research projects in job classification condition score and weight.

\section{Acknowledgements}

Project: the Department of Gansu Province Educational Science Planning Project 2015 "Integration and Symbiosis: Local Colleges and the Regional Economic Coordinated Development of Gansu Province" [GS [2015] GHB0953] initial results.

\section{References}

[1] Qin Wen. Local Colleges to serve the local economic and social development in Guangxi Problems and Countermeasures [J], Economic and Social Development, 2010 (5): 163

[2] Duan Xuehui. Local Colleges to enhance the capacity of social service Path of [J], Education, 2015 (9): 93

[3] Liu Haoyuan. local Social Services Research Universities - A Case Study of Nanchang University [D], Nanchang University graduate thesis, 2010: 41 